\title{
Pelaksanaan Pendidikan Formal Bagi Anak Didik di Lembaga Pembinaan Khusus Anak Kelas I Medan
}

\author{
Wahyu Ananda \\ Politeknik Ilmu Kemasyarakatan (POLTEKIP) \\ Badan Pengembangan Sumber Daya Manusia (BPSDM) \\ Kementerian Hukum Dan Hak Asasi Manuisa (Kemenkumham) \\ wahyuanandah@gmail.com
}

\begin{abstract}
Abstrak: Penelitian ini berfokus pada bagaimana pelaksanaan pendidikan Formal bagi anak didik di Lembaga Pembinaan Khusus Anak Kelas I Medan. Metode yang digunakan dalam penelitian ini adalah survei yang bersikap deskriptif dengan pendekatan kualitatif. Anak didik yang dimaksud di dalam penulisan ini adalah seorang anak yang telah melanggar ketentuanketentuan yang ada dalam masyarakat, sehingga mendapat pembinaan dan pendidikan agar mereka tidak melakukan pelanggaran terhadap ketentuan-ketentuan yang ada di masyarakat, pelaksanaan pembinaan dan pendidikan dalam Lembaga Pembinaan Khusus Anak, dalam istilah pemasyarkatan anak ini dikenal dengan sebutan "Anak Didik". Anak yang ditempatkan di Lembaga sebagai yang dimaksud dalam pasal (31) ayat (1) UUD 45 berhak memperoleh pendidikan dan latihan sesuai dengan bakat dan kemampuan serta hak lain berdasarkan peraturan perundang-undangan yang berlaku. Pendidikan yang diberikan bertujuan selain ikut mencerdaskan kehidupan bangsa dalam hal ini anak didik juga dalam pembinaan memberikan bekal setelah anak didik kembali ke masyarakat, mereka akan menjadi warga masyarakat yang baik sehingga tidak melakukan pelanggaran hukum lagi tetapi dapat berperan aktif dalam pembangunan.
\end{abstract}

Kata Kunci : Pendidikan Formal, Anak Didik Pemasyarakatan, Lembaga Pemasyarakatan Khusus Anak

Abstract: This study focuses on the implementation of formal education for juvenile in Medan Juvenile Prison. The method used in this study is a descriptive survey with a qualitative approach. The student referred to in this writing is a child who has violated the rules of society, so that he is obtaining education and education in order not to violate the conditions of society, the implementation of coaching and education in the Juvenile Prison, in this term the child is know as "the protege". Children who are placed as referred to in the chapter (31) of the clause (1) constitution 45 are entitled to education and practice according to talents and abilities and other rights based on accepted regulations. The education that is given is intended in addition to educating the nation in this regard, but education is also nurturing in educating the people when it comes back to society, they will be good citizens so as not to break the law again but to have an active role in the building.

Key Word: Formal Education, Protege Of Correctional, Juvenile Detention Center. 


\section{Pendahuluan}

Dalam pembukaan Undang-Undang Dasar 1945 dijelaskan bahwa salah satu tujuan dari pembangunan nasional adalah untuk mencerdaskan bangsa, agar dapat tercipta sumber daya manusia yang berkualitas, bertanggung jawab, maju dan mandiri sesuai dengan tatanan kehidupan masyarakat yang berdasarkan Pancasila. Dalam rangka mencerdaskan kehidupan bangsa tersebut, diperlukan suatu penyelenggaraan pendidikan yang dapat menjamin kelangsungan hidup bangsa dan negara. Dalam hal ini Penguatan pendidikan karakter dimulai dari lingkungan keluarga, sekolah, dan meluas ke dalam lingkungan masyarakat. Penguatan pendidikan karakter di era sekarang merupakan hal yang sangat penting untuk dilakukan mengingat banyaknya peristiwa yang menunjukkan terjadinya krisis moral baik di kalangan anak-anak, remaja, maupun orang tua (Sekolah \& Buton, 2020).

Dengan adanya perkembangan dunia kearah pembaharuan (modernisasi) dan adanya tuntutan keadaan ekonomi. Maka menyebabkan sedikitnya orang tua turut dalam semua gerak kemajuan masyarakat dan mencari nafkah sehingga banyak meninggalkan rumah tangga dengan mengakibatkan anak-anak kurang mendapatkan asuhan, bimbingan, pengawasan dan juga kasih sayang yang justru masih mereka butuhkan. Anak yang kurang mendapatkan perhatian kasih sayang dari orang tuanya akan merasa tidak aman, tidak bahagia dan banyak dipenuhi konflik batin serta mengalami kekecewaan yang terus menerus sehingga menjadi agresif. Kemarahan, kekecewaan serta dendam akan dilampiaskannya ke dalam bentuk perbuatan fisik seperti lari dari rumah, membolos yang akhirnya dapat memaksa anak itu untuk berhadapan dengan para penegak hukum. Hampir seluruh negara di dunia termasuk Negara Indonesia, timbulnya kenakalan pada anak dapat menimbulkan gangguan terhadap keamanan dan ketertiban Negara. Masyarakat merupakan bahaya yang dapat menimbulkan masalah kenakalan pada anak. Kenakalan remaja merupakan perilaku yang melanggar norma yang dilakukan oleh seseorang yang belum beranjak dewasa, yang berusia dibawah 18 tahun. Kenakalan yang dilakukan berjenjang dari hal yang serius seperti pembunuhan sampai hal kecil seperti membolos atau mencuri (Pratiwi \& Hastuti, 2017).

Masa remaja merupakan rentangan usia yang diliputi oleh ketidak stabilan jiwa anak, oleh karena itu berkaitan erat dengan juvenile delinquent (kenakalan remaja). Hubungan psikologis tersebut sejalan dengan kondisi lingkungan, akan tetapi yang kedua lebih dominan mendorong anak remaja menjadi delinquent (kenakalan remaja) (Riyadi, 2016). Dari sejumlah penegertian di atas dapat disimpulkan bahwa anak adalah seorang yang berada pada rentang usia antara 8 (delapan) tahun hingga 18 (delapan belas) tahun, pada usia tersebut anak berbeda dengan orang dewasa dalam hal kemampuan bertanggung jawab atas perbuatannya. Anak-anak yang menjadi Anak Didik Pemasyarakatan merupakan anak-anak yang berhadapan dengan hukum yang diputus oleh pengadilan dengan hukuman penjara, karena mereka telah melakukan tindak pidana dan perbuatannya dinilai membahayakan mayarakat. Anak Didik ini ditempatkan di Lembaga Pembinaan Khusus Anak (LPKA) (Chusniatun, 2018). Pelaksanaan pendidikan terhadap anak didik yang telah melakukan tindak pidana dapat dilaksanakan dengan mengacu pada Undang-Undang Nomor 12 Tahun 1995 Tentang Pemasyarakatan dan Undang-Undang Nomor 3 Tahun 1997 Tentang Pengadilan Anak.

Lembaga Pembinanaan Khusus Anak merupakan suatu instansi pembinaan terhadap anak yang melakukan tindak pidana berkewajiban untuk dapat melaksanakan 
tugas dan fungsi institusionalnya dalam melaksanakan penidikan agar dapat menyiapkan anak didik pemasyarakatan untuk berintigrasi secara sehat kepada masyarakat. Secara luas pendidikan dapat diartikan juga sebagai pembudayaan melalui masing-masing anak, yang dilahirkan dengan potensi belajar lebih besar daripada makhluk menyusui lainnya, di bentuk untuk menjadi anggota penuh dari suatu masyarakat, menghayati dan mengamalkan bersama-sama anggota yang lainnya dengan suatu kebudayaan tertentu (9264-22590-1-PB.pdf, n.d.). Anak-anak yang berada di Lembaga Pembinaan Anak pada umumnya tidak dapat mengikuti pendidikan di luar Lembaga secara bebas dan leluasa. Kegiatan pendidikan yang dilaksanakan di Lembaga Pembinaan Anak disamping berbentuk pendidikan sekolah dapat juga dilaksanakan dalam bentuk pendidikan keterampilan atau latihan kerja. Pendidikan yang dilaksanakan terhadap anak didik merupakan salah satu bentuk upaya pembinaan dalam rangka untuk mengembalikan perilaku dan sikap mental anak kearah yang baik.

Sesuai dengan hal tersebut penulis teratarik dengan pelaksanaan pemberian pendidikan formal kepada anak didik pemasyarakatan guna bekal hidup bermasyarakat nantinya setelah menjalani bimbingan, maka penulis mencoba membahas permasalahan tersebut terhadap Pelaksanaan Pendidikan Formal bagi anak didik di Lembaga Pembinaan Khusus Anak Kelas I Medan. Agar dapat mencapai tujuan dalam proes pendidikan yang baik, tidak terlepas dari permasalahan yang harus dipecahkan agar mencapai tujuan dan latar belakang masalah, penulis merumuskan permasalahan yakni: "Bagaimana pelaksanaan pendidikan formal bagi anak didik di Lembaga Pembinaan Khusus Anak Kelas I Medan?" adaun tujuan penelitian adalah untuk menegetahui pelaksanaan pendidikan formal bagi anak didik di Lembaga Pembinaan Khusus Anak Kelas I Medan. Manfaat penelitian agar diharapkan akan timbul rasa tanggung jawab dalam praktek pemenuhan pelaksanaan pendidikan formal di Lembaga Pembinaan Kusus Anak Kelas I Medan, sehingga petunjuk dan panduan bagi petugas pemasyarakatan dalam rangka pemenuhan pelaksanaan pendidikan formal yang ada di Lembaga Pembinaan Khusus Anak Kelas I Medan secara efektif.

\section{Metode Penelitian}

Penelitian ini menggunakan pendekatan kualitiatif yaitu berawal pada data dan bermuara pada kesimpulan (Bungin, 2001 : 18). Sasaran atau obyek penelitian dibatasi agar data yang diambil dapat digali sebanyak mungkin serta agar penelitian ini tidak dimungkinkan adanya pelebaran obyek penelitian, oleh karena itu kredibilitas dari peneliti sendiri menentukan kualitas dari penelitian ini (Bungin, 2001 :26). Penelitian yang digunakan pada karya tulis ini menggunakan metode deskriptif kualitatif dengna mencari informasi serta memperoleh gambaran sebanyak-banyaknya mengenai masalah-masalah yang timbul dengan memberikan gambaran tentang pelaksanaan penddikan formal bagi anak didik di Lembaga Pembinaan Khusus Anak Kelas I Medan. Sedangkan menurut Lexy j. Moleong (2007) mendefinisikan penelitian deskriptif kualitatif adalah penelitian yang bermaksud untuk memahami fenomena tentang apa yang dialami oleh subjek penelitian, misalnya perilaku, persepsi, motivasi, tindakan, dll., secara holistik dan dengan cara deskripsi dalam bentuk kata-kata dan bahasa, pada suatu konteks khusus yang alamiah dan dengan memanfaatkan berbagai metode alamiah (Arikunto, 2011). 


\section{Hasil dan Pembahasan}

Proses penelitian ini dengan menggunakan data-data dan informasi selengkaplengkapnya dengan menggunakan cara-cara sebagai berikut. Dalam memperoleh data yang dibutuhkan sebagai bahan pembuatan laporan penelitian, menggunakan beberapa teknik, cara atau metode yang dilakukan oleh peneliti dan disesuaikan dengan jenis penelitian kualitatif yakni: (1) Observasi, (2) Kepustakaan, (3) Analisis dan refleksi.

Tabel 1. Data Penghuni Berdasarkan Usia Dalam 5 ( Lima) Tahun Terakhir

\begin{tabular}{|c|c|c|c|c|c|c|c|}
\hline \multirow{2}{*}{ No. } & \multirow{2}{*}{ Usia } & \multicolumn{6}{|c|}{ Tahun } \\
\hline & & 2015 & 2016 & & & 2018 & 2019 \\
\hline \multirow{5}{*}{1.} & $8 \mathrm{~S} / \mathrm{D} 12$ & & & & & & \\
\hline & Anak Pidana & 1 & 2 & 1 & 1 & & 3 \\
\hline & Anak Tahanan & 1 & - & - & - & & - \\
\hline & Anak Negara & 1 & 1 & 2 & 1 & & 1 \\
\hline & Anak Sipil & - & - & - & - & & - \\
\hline \multirow{5}{*}{2.} & 13 S/D 15 & & & & & & \\
\hline & Anak Pidana & 48 & 39 & 20 & 28 & & 35 \\
\hline & Anak Tahanan & 12 & 6 & 9 & 2 & & 6 \\
\hline & Anak Negara & 6 & 4 & 3 & 5 & & 9 \\
\hline & Anak Sipil & - & - & - & - & & - \\
\hline \multirow{5}{*}{3.} & 16 S/D 18 & & & & & & \\
\hline & Anak Pidana & 163 & 71 & 80 & 120 & & 145 \\
\hline & Anak Tahanan & 23 & 20 & 11 & 23 & & 15 \\
\hline & Anak Negara & 2 & 5 & 5 & 4 & & 2 \\
\hline & Anak Sipil & - & - & - & - & & - \\
\hline \multirow{6}{*}{4.} & $19 \mathrm{Ke}$ Atas & & & & & & \\
\hline & Anak Pidana & 2 & - & - & - & & - \\
\hline & Anak Tahanan & - & - & - & - & & - \\
\hline & Anak Negara & - & - & - & - & & - \\
\hline & Anak Sipil & - & - & - & - & & - \\
\hline & Jumlah & 259 & 148 & 131 & 184 & & 216 \\
\hline
\end{tabular}

Sumber : Sub.Seksi Registrasi (2019)

Berdasarkan data di atas dapat kita ketahui bahwa keadaan penghuni Lembaga Pembinaan Khusus Anak Kelas I Medan sudah mengalami penurunan jumlah penghuni berdasarkan usia yang cukup signifikan namun tahun-tahun berikutnya mengalami kenaikan jumlah penghuni secara bertahap. Kenaikan jumlah penghuni berdasarkan usia ini dapat dilihat berdasarkan usia anak didik dari Tahun 2015 yang berjumlah 259 orang anak, pada tahun 2016 terjadi penurunan yang drastis dengan jumlah menjadi 148 orang anak, ketika tahun 2018 jumlah penghuni mengalami kenaikan dengan jumlah 184 orang anak dan pada tahun 2019 jumlah anak meningkat lagi menjadi 216 orang anak. Dengan kapasitas 220 orang anak, usia anak didik pemasyarakatan adalah anak yang berusia 
berkisar 10 sampai dengan 18 tahun, jumlah anak didik tahun 2019 yakni: (1) Anak Tahanan = 21 orang, (2) Anak Pidana = 183 orang, (3) Anak Negara = 12 orang, (4) Anak Sipil = - orang, data diatas menunjukan bahwa jumlah penghuni yang berjumlah 216 orang anak yang berada di bawah kapasitas 220 orang anak tersebut, sudah cukup ideal dalam pelaksanaan pembinaan dan pengawasan keamanan yang baik.

Tabel 2. Data Penghuni Berdasarkan Golongan

\begin{tabular}{ccc}
\hline No. & Status & Jumlah \\
\hline 1. & Tahanan & \\
& AI & 2 \\
& AII & 8 \\
& AIII & 9 \\
& AIV & 1 \\
& AV & 1 \\
2. & Anak Pidana & \\
& BI & 169 \\
& BIIa & - \\
& BIIb & - \\
& BIII & 12 \\
3. & Anak Negara & - \\
\hline 4. & Anak Sipil & 216 Anak \\
\hline
\end{tabular}

Sumber: Sub Seksi Registrasi (2019)

Status anak di Lembaga Pembinaan Khusus Anak Kelas I Medan ada yang berstatus tahanan dan anak pidana. Berdasarkan golongan anak yang berstatus tahanan dan anak pidana. Berdasarkan golongan anak yang berstatus tahanan A1 (Tahanan Penyidik), AII (Tahanan Penuntut Umum), AIII (Tahanan Hakim Pengadilan Negeri), AIV (Tahanan Hakim Pengadilan Tinggi), AV (Tahanan Hakim Mahkamah Agung). Dari total anak berstatus tahanan yang berjumlah 21 anak, didominasi oleh anak yang berstatus tahanan AIII (Hakim Pengadilan Negri) yang berjumlah 9 anak dan anak yang berstatus anak pidana berdasarkan golongan adalah BI (pidana lebih dari satu tahun), BIIa (hukuman pengganti denda). Dari total anak berstatus anak pidana yangberjumlah 195 anak, didominasi oleh anak pidana BI (pidana lebih dari satu tahun) yang berjumlah 169 anak pidana.

\section{a. Pelaksanaan Pendidikan Formal yang dilaksanakan di Lembaga Pembinaan Khusus Anak Kelas I Medan}

Sistem pembinaan anak di Lembaga Pembinaan Khusus Anak Kelas I Medan merupakan sistem terpadu yang baik, dikatakan demikian karena dalam realisasinya pola pembinaan anak secara khusus di dasarkan pada pendidikan atau kemahiran anak didik yang didalam tahap awal dijadikan landasan pembagian kelompok anak dalam kelompokkelompok kecil yang sekaligus digunakan untuk penempatan anak didik di kamar-kamar, dengan pembagian yakni: (a) Kelompok berpendidikan Sekolah Dasar (SD), (b) 
Kelompok berpendidikan Sekolah Menengah Pertama (SMP), (c) Kelompok berpendidikan Sekolah Menengah Umum (SMU), (d) Kelompok yang memiliki kemahiran sesuai bakat minatnya dikenal dengan Pendidikan Luar Sekolah (PLS). Pembagian kelompok berdasarkan pendidikan pada tahap awal tersebut selain dipergunakan untuk penentuan kamar serta fasilitas lainnya dengan penggolongan yakni: AI, AII, AIII, BI, BII, BIIb, BIII, Anak Negara dan Anak Sipil.

Berikut jumlah murid Sekolah Dasar Istimewa pada Bulan Juni 2019 berjumlah 32 orang yang terdiri dari:

Tabel 3. Keadaan Jumlah Peserta Didik Sekolah Dasar (SD) Istimewa

\begin{tabular}{cc}
\hline Kelas & Sekolah Dasar (SD) Istimewa \\
\hline 1 & - \\
2 & - \\
3 & - \\
4 & 11 \\
5 & 13 \\
6 & 8 \\
\hline Jumlah & 32 \\
\hline
\end{tabular}

Sumber: Sub Seksi Registrasi, (2019)

Dari tabel di atas dapat di lihat bahwa untuk Sekolah Dasar Kelas I Medan sampai III tidak terdapat anak didik yang mengikuti di kelas tersebut, hal ini disebabkan pada dasarnya anak didik dalam Lembaga Pembinaan Khusus Anak Kelas I Medan, pernah mengikuti pendidikan sekolah tingkat dasar umum karena keadaan ekonomi orang tua, lingkungan dan pergaulan sehingga mereka tidak dapat melanjutkan pendidikan tersebut dan akhirnya mereka melakukan pelanggaran hukum. Selama anak didik di Lembaga, anak didik diperkenankan untuk menggunakan pakaian bagus, karena apabila digunakan pakaian penghuni, tentunya akan cepat sekali rusak, anak didik hanya memperoleh 1 stel selama di dalam lembaga. Namun pada saat apel mereka diwajibkan menggunakan pakaian yang sudah ditentukan bagi anak didik yang bersekolah mereka dapat langsung menggunakan pakaian sekolah.

Berikut jumlah murid SMP Istimewa pada bulan Juni 2019 berjumlah 40 orang yang teridi dari:

Tabel 3. Keadaan Jumlah Peserta Didik Sekolah Menengah Pertama (SMP) Istimewa

\begin{tabular}{cc}
\hline Kelas & Sekolah SMP Istimewa \\
\hline 1 & 11 \\
2 & 10 \\
3 & 19 \\
\hline Jumlah & 40 \\
\hline Sumber: Sub Seksi Registrasi (2019)
\end{tabular}

Pada pelaksanaan pendidikan formal bagi anak didik yang ditingkat Sekolah Menengah Pertama (SMP) tidak berbeda dengan yang diterapkan pada sekolah Tingkat Sekolah Dasar. Setelah anak didik menyelesaikan pendidikan tentunya anak didik mendapat ijazah yang disahkan oleh Dinas Pendidikan Nasional Medan. 
Berikut jumlah murid Sekolah Menengah Pertama (Kejar Paket B) pada 19 Juni 2019 berjumlah 25 orang yakni:

Tabel 3. Keadaan Jumlah Peserta Didik Kejar Paket B

\begin{tabular}{lc}
\hline Program & Kejar Paket B \\
\hline Jumlah & 25 \\
\hline Sumber: Sub Seksi Registrasi (2019)
\end{tabular}

Pada tabel di atas terlihat adanya Program Kejar Paket B setingkat SMP hal ini disebabkan ada anak didik sendiri yang menginginkan sendiri untuk ditempatkan dalam kelompok Kejar Paket B. Dalam memperoleh pendidikan formal anak didik tergabung dengan Anak Pidana, Anak Negara, dan Anak Sipil. Tetapi khusus untuk tidur dipisah antara Anak Pidana dan Anak Negara. Sistem ini patut dikembangkan karena sejalan dan selaras dengan tujuan pemindanaan dan pembinaan anak didik yakni dalam rangka membentuk anak didik sebagai Warga Binaan Pemasyarakatan agar menjadi manusia seutuhnya, menyadari kesalahannya, memperbaiki diri, dan tidak mengulangi tindak pidana sehinga dapat diterima kembali oleh lingkungan masyarakat dapat aktif berperan dalam pembangunan, dan dapat hidup secara wajar sebagai waga yang baik dan bertanggung jawab.

Proses pendidikan Formal yang meliputi Sekolah dasar (SD), Sekolah Menengah Tingkat Pertama (SMP), dan Sekolah Menengah (SMU). Selain itu meliputi pendidikan luar sekolah yang meliputi pendidikan Life Skill I ketrampilan yang dilaksanakan di Lembaga dengan kesemua itu tentunya bekerja sama dengan Pihak ke III yaitu Penyidik, Kejaksaan, Pengadilan, Dinas Kesehatan, Dinas Agama, Dinas Tenaga Kerja, Dinas Perindustrian dan Perdagangan, Dinas Pendidikan Nasional, Instansi Swasta dan Lembaga Swadaya Masyarakat (LSM), Plan Internasional. Kerjasama tersebut sangat mendukung pola pembinaan yang ada terutama Pendidikan Formal. Sekolah Luar Biasa bagi yang tidak mengikuti pendidikan formal dilakukan pada Sekolah Luar Biasa (SLB) yang diadakan pada setiap hari jum'at dan sabtu. 
Tabel 4. Jadwal Pelajaran Anak Didik

\begin{tabular}{cccc}
\hline Waktu & Senin & Selasa & Rabu \\
\hline $08.00-08.35$ & B.Indonesia & Matematika & IPA \\
$08.35-09.10$ & B.Indonesia & Matematika & IPA \\
$09.10-09.45$ & B.Indonesia & Matematika & IPA \\
$09.45-10.15$ & Istirahat & Istirahat & Istirahat \\
$10.15-10.50$ & PKN & Agama Islam & IPS \\
$10.50-11.25$ & PKN & Agama Islam & IPS \\
$11.25-12.00$ & PKN & Agama Islam & IPS \\
Waktu & Kamis & Jum'at & Sabtu \\
\hline $08.00-08.35$ & B.Inggris & Penjaskes/Teori & Pramuka \\
$08.35-09.10$ & B.Inggris & Olahraga & Pramuka \\
$09.10-09.45$ & B.Inggris & Olahraga & Pramuka \\
$09.45-10.15$ & Istirahat & Istirahat & Istirahat \\
$10.15-10.50$ & Komputer & Budi Pekerti & SBK \\
$10.50-11.25$ & Komputer & & SBK \\
$11.25-12.00$ & Komputer & & \\
& & & \\
\hline
\end{tabular}

\section{Sumber: Sub Seksi Reistrasi (2019)}

Proses belajar mengajar di sekolah dimulai dari pukul 08.00-12.00 WIB, hal ini disebabkan karena kegiatan di dalam Lembaga Pembinaan Khusus Anak Kelas I Medan menyesuaikan aktifitas yang ada. Dan proses belajar mengajar di ruang kelas hanya dilaksanakan dari hari Senin sampai dengan Kamis, sedangkan pada hari Jum'at dan Sabtu pembinaan dalam bentuk kegiatan Olahraga dan Pramuka. Untuk kegiatan Pramuka di Lembaga Pembinaan Khusus Anak Kelas I Medan dalam pelaksanaan latihan ketrampilan kepramukaan dengan mendatangkan pelatih dari luar dan kegiatan dilaksanakan pada setiap Sabtu pagi. Kegiatan Olahraga sepak bola dilaksanaan setiap hari Sabtu di mulai dari pukul 09.30 sampai pukul 11.00 WIB, dibawah pengawasan dari Guru.

Berikut adalah table hasil belajar yang diberikan kepada anak didik Pemasyarakatan diperoleh data-data sebagai berikut:

Tabel 5. Jumlah Kelulusan Anak Didik Pemasyarakatan

\begin{tabular}{ccccccc}
\hline Tahun & \multicolumn{3}{c}{ SD } & \multicolumn{2}{c}{ SMP } & \multicolumn{2}{c}{ Paket B } \\
\cline { 2 - 7 } 2015 & Lulus & Tidak & Lulus & Tidak & Lulus & Tidak \\
2016 & 25 & 1 & 13 & - & 12 & - \\
2017 & 9 & - & 7 & - & 6 & - \\
2018 & 7 & - & 25 & - & 1 & - \\
2019 & 8 & - & 21 & - & 2 & - \\
\hline Jumlah & 8 & - & 27 & - & 5 & - \\
\hline
\end{tabular}

Sumber: Sub Seksi Registrasi, (2019) 
Dapat kita lihat dari data-data tersebut di atas bahwa tingkat kelulusan sangat tinggi dan ada pula yang tidak lulus, hal ini disebabkan Anak Didik tersebut telah selesai masa pidananya, tentunya dari sekolah senidiri mengharapkan kepada Anak Didik yang telah bebas agar mereka melanjutkan pendidikan di luar Lembaga Pemasyarakatan.

Berdasarkan hasil penelitian tentang Pelaksanaan Pendidikan Formal Bagi Anak Didik Pemasyarakatan Kelas I Medan sudah sesuai dengan Undang-Undang Republik Indonesia Nomor 20 Tahun 2003 Tentang Sistem Pendidikan Nasional mengenai jalur, jenjang, dan jenis pendidikan, Pasal 14: "Jalur, jenjang pendidikan formal terdiri atas pendidikan dasar, pendidikan menengah, pendidikan tinggi". Pasal 16: "Jalur, jenjang dan jenis pendidikan dapat diwujudka dalam bentuk satuan pendidikan yang diselenggarakan oleh Pemerintah, pemerintah daerah, dan/atau masyarakat. Di Lembaga embinaan Khusus Anak Kelas I Medan, program pendidikan formal dengan jenjang pendidikan dasar dimulai dari kelas 4 sampai dengan kelas 6 dan jenjang pendidikan menengah dimulai dari kelas 1,2, dan 3. Sementara untuk jenjang pendidika tinggi tidak ada dikarenakan anak didik Pemasyarakatan seusia jenjang pendidikan tinggi rata-rata telah melaksanakan pendidikan tersebut di luar Lembaga Pemasyarakatan. Tenaga pengajar untuk pendidikan formal di Lembaga Pemasyarakatan menggunakan jasa Pegawai Lembaga Pembinaan Khusus anak Kelas I Medan, pelaksanaan pendidikan formal di Lembaga pembinaan Khusus Anak Kelas I Medan berbeda dengan pendidikan formal di luar Lembaga Pemasyarakatan. Diluar Lembaga Pemasyarakata pendidikan formal tidak bersifat memaksa, sementara di dalam Lembaga Peemasyarakatan merasa terpaksa untuk mengikuti pendidikan formal. Lembaga Pembinaan Khusus Anak Kelas I Medan sendiri mewajibkan bagi setiap anak didik Peamsyarakatan untuk mengikutii program pembinaan berupa pendidikan formal.

\section{Kesimpulan dan Saran}

a. Kesimpulan

Dari uraian penjabaran pada bab-bab terdahulu, maka penulis akan mengemukakan beberapa kesimpulan sebagai tinjauan dari keseluruhan penulisan. Pelaksanaan Pendidikan Formal di Lembaga Pembinaan Khusus Anak Kelas I Medan telah sesuai dengan Undang-Undang Republik Indonesia Nomor 20 Tahun 2003 Tentang Sistem Pendidikan Nasional dimana disebutkan dalam pasal (14) dan (16). Pendidikan Formal di Lembaga Pembinaan Khusus Anak Kelas I Medan menjalankan jenjang pendidikan dasar dimulai dari kelas 4 sampai dengan kelas 6, sementara untuk pendidikan menengah dimulai dari kelas 1 sampai dengan kelas 3 . Tenaga pengajar pendidikan formal menggunakan jasa Petugas Lembaga Pembinaan Khusus Anak Kelas I Medan. Adapun masalah yang ditemukan oleh peneliti mengenai pelaksanaan pendidikan formal di Lembaga Pembinaan Khusus Anak Kelas I Medan diataranya sebagai berikut: (1) Pemberian yang meliputi pakaian seragam, perlengkapan sekolah dan pramuka belum terpenuhi secara baik dan maksimal karena terbentuk dengan anggaran. (2) Bimbingan lanjut setelah usai menjalani pembinaan tidak terkontrol dan tidak memperoleh perhatian dari pemerintah lagi sehingga sistem pembinaan yang cukup baik dan proaktif di Lembaga Pembinaan Khusus Anak Kelas I Medan menjadi tidak berarti lagi.

b. Saran

Beberapa saran dari penulis mengenai pelaksanaan pendidikan formal di Lembaga Pembinaan Khusus Anak Kelas I Medan yang berguna kemajuan dan penyempurnaan 
keberadaan pelaksanaan pendidikan formal, Peranan guru atau pembina sebagai pengajar dalam setiap kegiatan belajar mengajar tidak mungkin diabaikan, tidak akan ada pendidikan tanpa ada seorang guru, jadi guru adalah penggerak dalam proses belajar mengajar. Menjadi guru tidak semudah membalik telapak tangan perlu adanya pendidikan khusus dan syarat-syarat yang harus dilalui untuk menjadi guru atau pembina, mengingat peran seorang guru berat diantaranya membina, membimbing, memberikan ilmu pengetahuan kepada anak didiknya agar menjadi generasi penerus bangsa yang mampu membangun diri dan bangsa untuk maju dan berkembang, jadi begitu berat harapan yang disandang guru sebagai pendidik. Guru yang berada di Lembaga Pembinaan Khusus Anak Kelas I Medan tentunya mendapat peran ganda atau dwifungsi disitu sisi menjadi guru/pendidik dan satu sisi lainnya adalah Petugas Pemasyarakatan. Sehingga dalam pelaksanaan pendidikan kepada anak didik sering terabaikan, sebagai misalnya apabila sedang mendapatkan piket malam tentunya besok hari tidak bekerja, namun dalam kegiatan program pendidikan formal harus tetap berjalan, tentunya dengan begitu kegiatan pengajaran bagi anak didik tidak berjalan, karena pengajaran sedang lepas piket. Oleh sebab itu bagi Petugas pendidikan sebaiknya ada pengkhususan untuk tidak melaksanakan piket malam agar pelaksanaan pendidikan tidak terganggu.

\section{Daftar Pustaka}

9264-22590-1-PB.pdf. (n.d.). Arikunto. (2011). Deskriptif Kualitatif. 48-61.

Chusniatun. (2018). Sistem Perlindungan Hukum Bagi Anak di Lembaga Pemasyarakatan Dalam Perspektif Konvensi Internasional Hak-Hak Anak. 30(01), 103-132.

Pratiwi, I., \& Hastuti, D. (2017). Kenakalan Pada Remaja Andikpas (Anak Didik Lapas): Pengaruh Komunikasi Orang Tua atau Self-Esteem? Jurnal Ilmu Keluarga Dan Konsumen, 10(1), 36-46. https://doi.org/10.24156/jikk.2017.10.1.36

Riyadi, A. (2016). Hubungan Konsep Diri dengan Kenakalan Anak Jalanan pada Rumah Singgah Putra Mandiri Semarang. Psympathic: Jurnal Ilmiah Psikologi, 3(1), 23-34. https://doi.org/10.15575/psy.v3i1.1097

Sekolah, P. G., \& Buton, U. M. (2020). Implementasi pendidikan karakter disiplin siswa di sekolah dasar kota baubau. 5.

Barnadib, Imamm (1982). Pemikiran tentang pendidikan baru. Yogyakarta: Andi Offset

Denied, Education. (2003) Pendidikan yang terabaikan. Inggris: Katarina Tomasevski.

Marzuki, Saleh. (2010) Pendidikan formal. Bandung: PT Remaja Rosdakarya

Schaefer, Charles. 1989 Cara efektif mendidik dan mendisiplinkan anak. Jakarta: Mitra Utama

Saraswati, Rika. (2009) Hukum perlindungan anak di indonesia. Bandung Citra Arditya Bakti

Undang-Undang Nomor 12 Tahun 1995, Tentang Pemasyarakatan

Undang-Undang Nomor 39 Tahun 1999, Tentang Hak Asasi Manusia

Undang-Undang Nomor 3 Tahun 1997, Pengadilan Anak

Undang-Undang Nomor 20 Tahun 2003 Tentang Sistem Pendidikan Nasional

Undang-Undang Nomor 23 Tahun 2002 Tentang Perlindungan Anak. 